\author{
Military Technical College \\ Kobry El-Kobbah, \\ Cairo, Egypt.
}

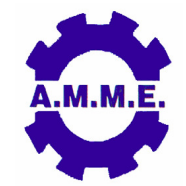

\title{
ROLLER AXLE ENHANCEMENT FOR TRACK GUIDE DESIGN
}

\author{
M. E. Abo-Elnor*
}

\begin{abstract}
Track rollers are usually subjected to heavy stresses during guide and launching processes. Design of such roller systems to withstand high dynamic loads during guiding and launching processes may lead to massive structure such in mobile bridge launcher. The feature-based modeling technology in computer aided design (CAD) has been widely studied, which greatly facilitates the manufacture of the design. In this study computer aided engineering (CAE) techniques was used in design of a smart bridge launcher which insure satisfaction distribution of the applied dynamic loads during launching and enhancing roller system design to cover overestimated manufacturing tolerances deformations. Results show that roller system design has significant effect on rolling resistance and overall launching process.
\end{abstract}

\section{KEY WOORDS}

Self-aligning; track guide; tandem rollers assembly; concentric axle

* Egyptian Armed forces. 


\section{INTRODUCTION}

In the production of a relatively large mechanism such in mobile bridges, the process of assembly is not fairly simple to merely bringing the individual components of the mechanism with no manual adjustment. However, it is not particularly difficult to attain the precise dimensions of such mechanism links that are made up of several parts which, when connected, might have their tolerances added together beyond the permissible value. It is, therefore, very important to select the design of a mechanism so that the accuracy requirements should be relatively low and hence having their links self-aligning [1].

Not only the production accuracy and precise assembly of mechanism individual components have significant effect on the mechanism performance and overall moving resistance but also service life, elastic performance, thermal expansion and components wear may cause general failure in such mechanisms performance.

In rapid deployment (mobile) bridge launcher, figure (1), having tandem rollers to insure fairly distribution of track load over guide rollers is not sufficient to overcome misalignment of launching track which may exist due to production accuracy, assembly tolerance [2] and operational deformation. Track rollers assembly enhancement is developed in this publication and qualitative comparison between traditional tandem rollers assembly with concentric axle configuration and the developed one with eccentric axle configuration is carried out to represent the advantage of the proposed assembly over the traditional one.

\section{MATERIALS AND METHODS}

In rapid deployment mechanical bridges, the launching mechanism and process is one of the important issues to decrease launching time and effort during bridge laying process. The bridge main girder includes track guide is made of several components assembled together even by welding or bolted connection. Due to the large size of the bridge which sometimes reaches 30 meter long, one meter depth, and 3 meter width [3], deflection of the track guide can be exists and affects launching process. Tandem rollers assembly, figure (2), is designed to establish fairly distribution of track reactions during launching of such bridges but it cannot stands for extra production tolerances or over estimated elastic or plastic deflection of girder track guide during launching process.

\section{TRADITIONAL TRACK ROLLERS ASSEMBLY}

In traditional tandem track rollers assembly, roller axle is of concentric configuration i.e. the two sides' pair of rollers assembly is in the same axis of roller axle. And hence the coupling rollers assemblies of front and rear rollers groups are at the same level as shown in figure (3). To examine the performance of track guide rollers in high deflection or tolerated production quality, a $5 \mathrm{~mm}$ deflection was introduced allover a 5 meter long girder, figure (4). 
As shown in figure (4), an overlap of about $4.5 \mathrm{~mm}$ is established at one roller pair which is impossible to valid in practical and hence failure of bridge launching process should occurs, as will discussed later on in this publication.

\section{PROPOSED DEVELOPED TRACK ROLLERS ASSEMBLY}

In order to decrease the effect of large deformation and production tolerances, a developed rollers assembly is introduced in this study. The key point of the proposed development is to replace the concentric rollers axle with an eccentric one as shown in figure (5).

As done in the traditional rollers discussed in the previous section, a $5 \mathrm{~mm}$ deflection was introduced along a 5 meter track guide. The geometric assembly of the system shows a gap of about $0.75 \mathrm{~mm}$ when using the developed axle, figure (6), which reveals the advantage of the proposed eccentric axle over the traditional concentric one. Motion analysis of launching process was simulated using Solid Works motion analysis and simulation module [4]. Both traditional and developed rollers assembly were analyzed for normal track guide and deformed one. Rollers reaction was calculated along with launching resistance forces during launching process with 50 $\mathrm{mm} / \mathrm{s}$ launching speed.

\section{RESULTS AND DISCUSSION}

Forces acting on each track rollers assembly in front axle and rear axle, figure (7), are blotted for both healthy and deformed bridge girder structure. Reaction forces acting on each axle assembly is logged during girder movement for both healthy and deformed track guide considering both traditional rollers assembly (concentric axle) and developed rollers assembly (eccentric axle), figure (8, 9, 10 and 11).

Results illustrated in figures $(8,9,10$, and 11) show that for healthy structure both concentric and eccentric axle configurations conduct steady state reactions without any significant difference between both configurations. In the case where track guide deformation takes place, forces acting on track rollers with traditional rollers assembly (concentric axle) shows severe disturbance on reaction forces before failure of the launching process, while in the case of using the proposed developed rollers assembly (eccentric axle), nearly normal distribution of reaction forces over both front and rear axle rollers after contact establishment can be easily shown.

To conclude this analysis, resistance forces of launching mechanism is plotted during launching process for normal and deformed track guide using traditional and developed rollers assembly, figure (12). Results show that with normal (healthy) track guide; both traditional and developed rollers assembly faces almost same resistance. For the deformed track guide, traditional rollers assembly (concentric axle) faces sever resistance and failure in launching process while the developed rollers assembly (eccentric axle) faces high resistance and succeed to complete the launching process. 
Stress analysis of roller axles with deformed track was carried out to reflect the effect of movement resistance and track deformation over axle's stresses. Figure (13) illustrates stress distribution on concentric axle configuration while figure (14) illustrates stress distribution on the proposed eccentric axle configuration at the same launching speed and time. Figures (13 and 14) reveal low stress on the proposed eccentric axle rather than the traditional concentric axle.

\section{CONCLUSIONS}

A developed rollers assembly is introduced using an eccentric axle to avoid production and assembly tolerance problems of launching rapid deployment mechanical bridges. Numerical analysis of the proposed system was carried out along with the traditional tandem rollers assembly with concentric axle. Results show that for healthy (non-deformed) track guide, the effect of using eccentric axle is not significant over the traditional one. While with deformed track guide, the proposed developed rollers assembly using eccentric axle succeeds to complete launching process with high resistance. As a result, the developed rollers assembly with eccentric axle can be used to solve launching problems of tolerances and deformation.

\section{REFERENCES}

[1] Self-Aligning Mechanisms, L. Reshetov, Mir Publishers, Moscow, 1986

[2] Larsen, Glen C., A Generalized Approach to Kinematic Modeling for Tolerance Analysis of Mechanical Assemblies, Brigham Young University Master's Thesis, August 1991.

[3] http://www.army-technology.com/contractors/engineering/cnim

[4] DS SolidWorks, USA, 2011 

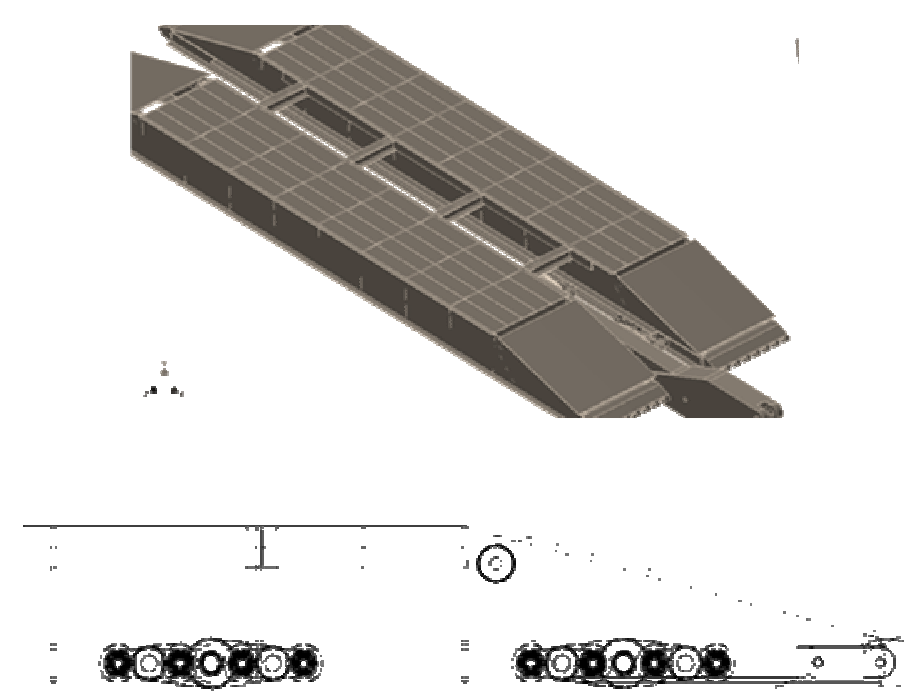

Fig. (1) Rapid launcher with traditional tandem rollers.

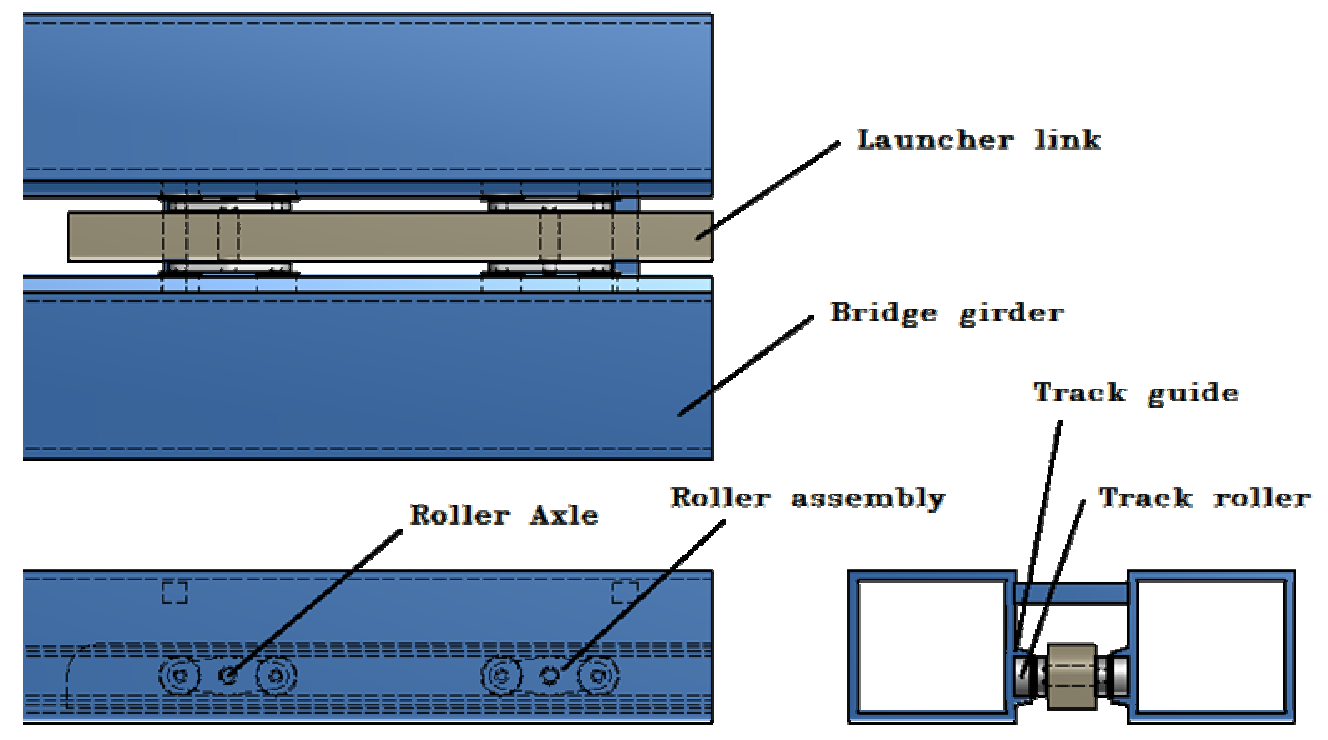

Fig. (2) Launcher mechanism components.

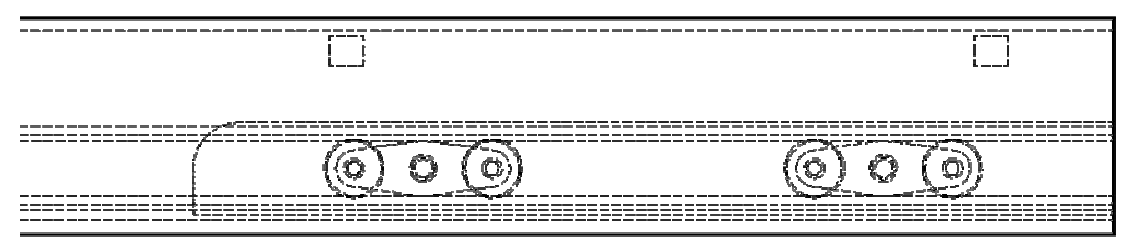

Fig. (3) Traditional rollers assembly with normal track guide. 

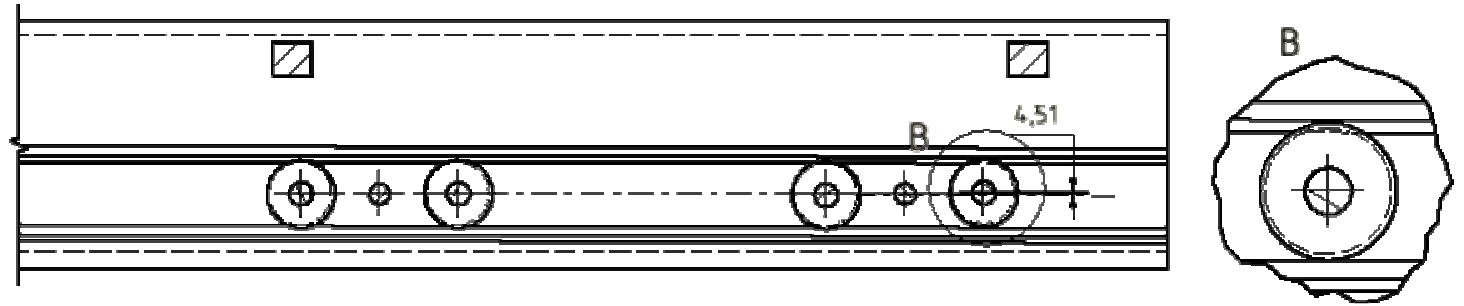

Fig. (4) Traditional rollers assembly with deformed track guide.
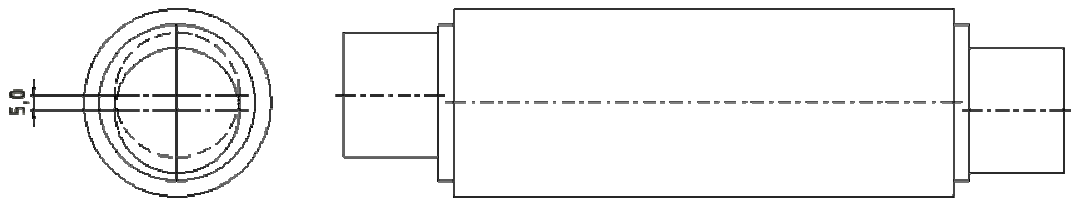

Fig. (5) $5 \mathrm{~mm}$ eccentric rollers axle.
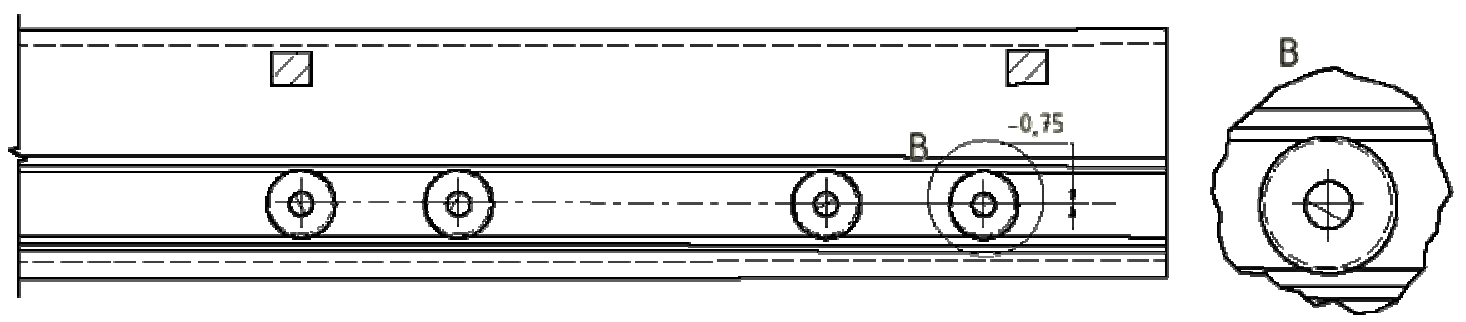

Fig. (6) Developed rollers assembly with deformed track guide.

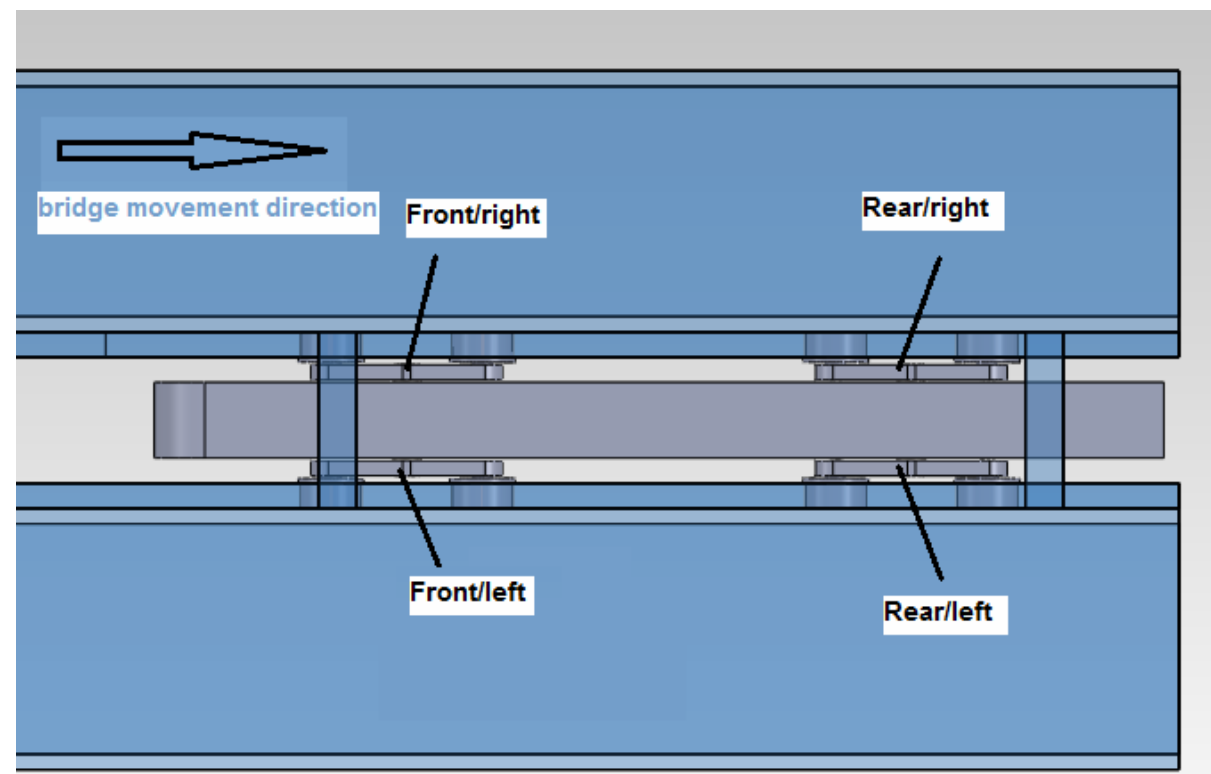

Fig. (7) Roller axle's arrangement. 


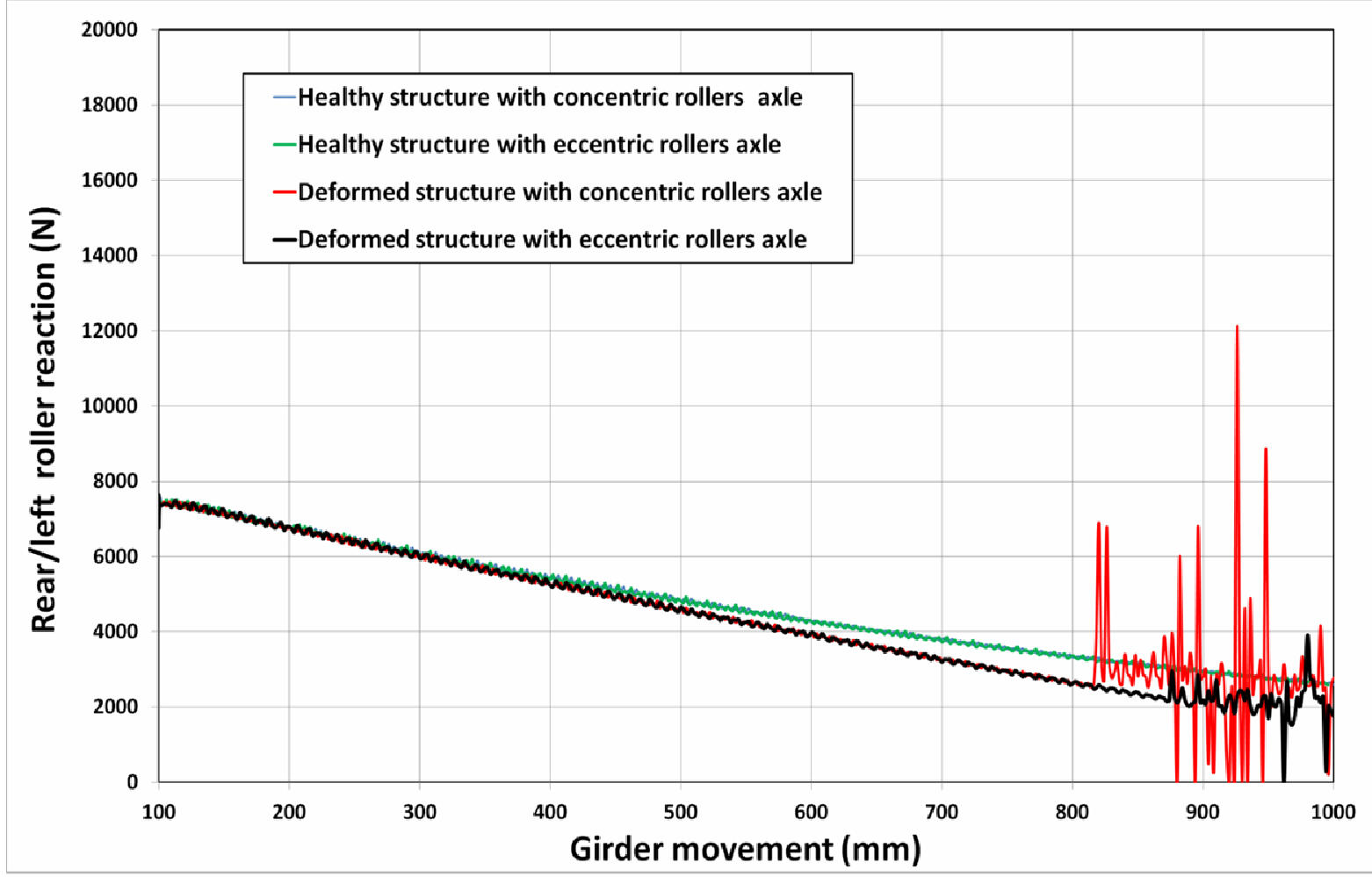

Fig. (8) Rear left axle reactions.

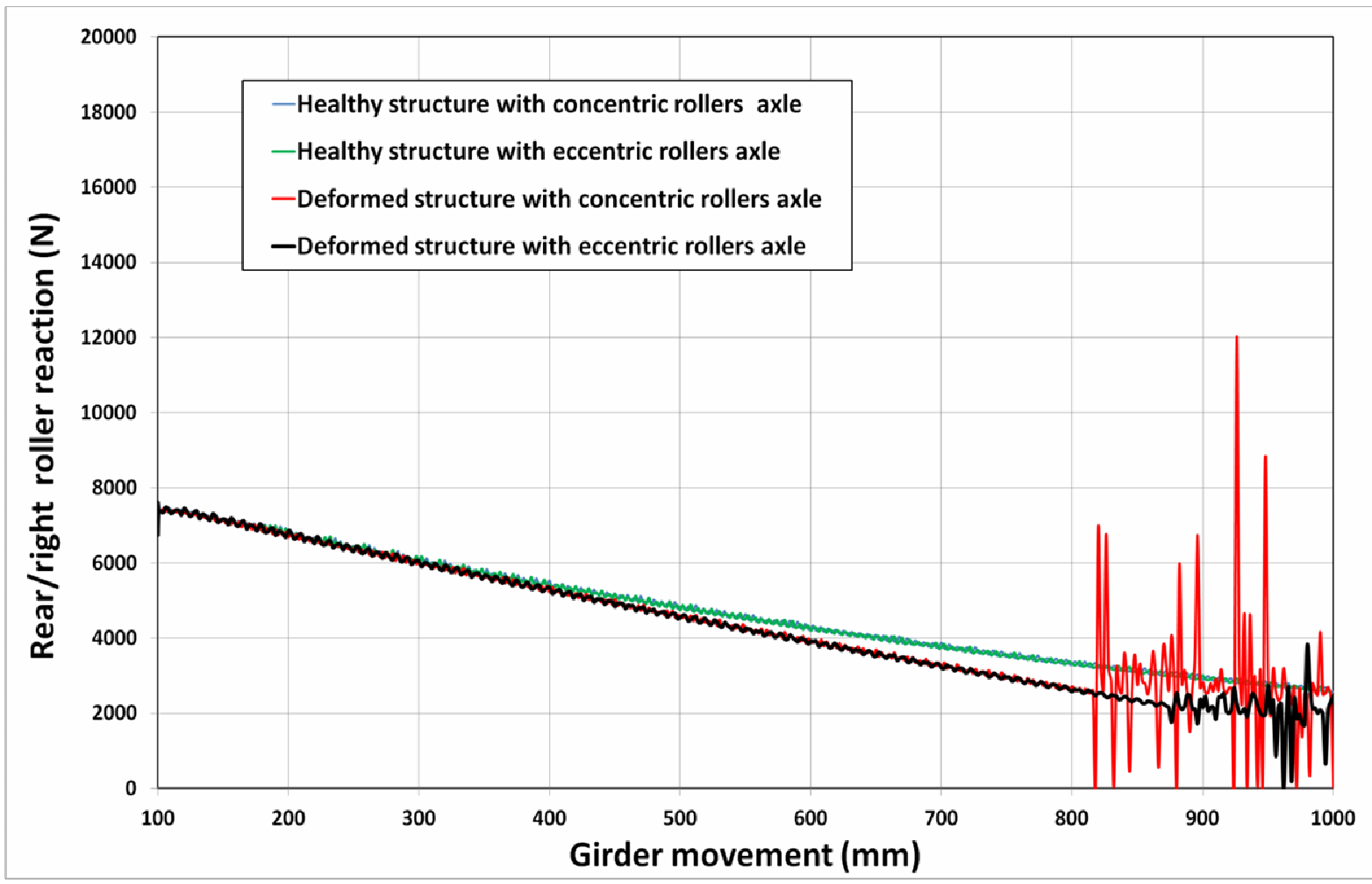

Fig. (9) Rear right axle reactions. 


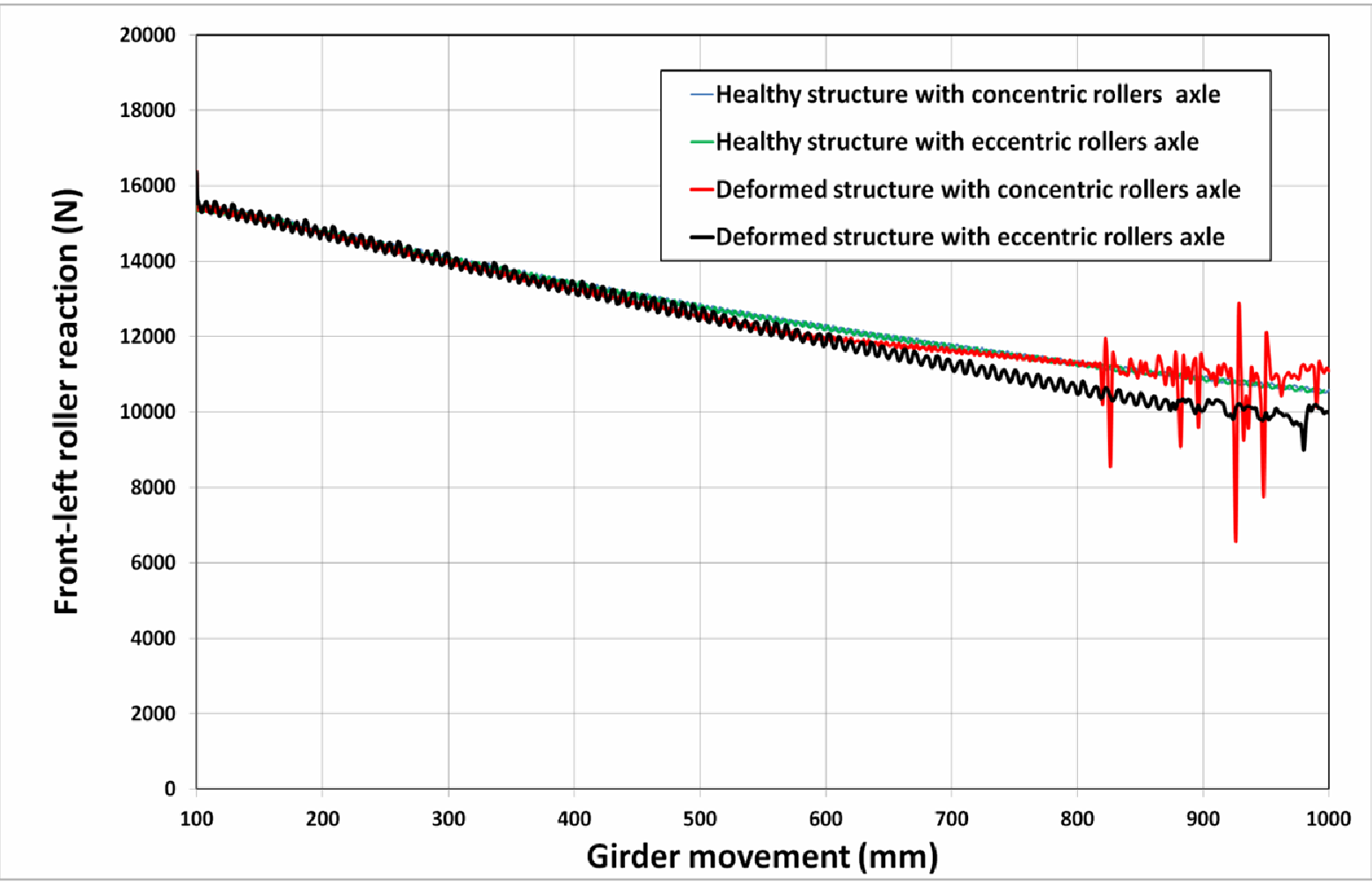

Fig. (10) Front left axle reactions.

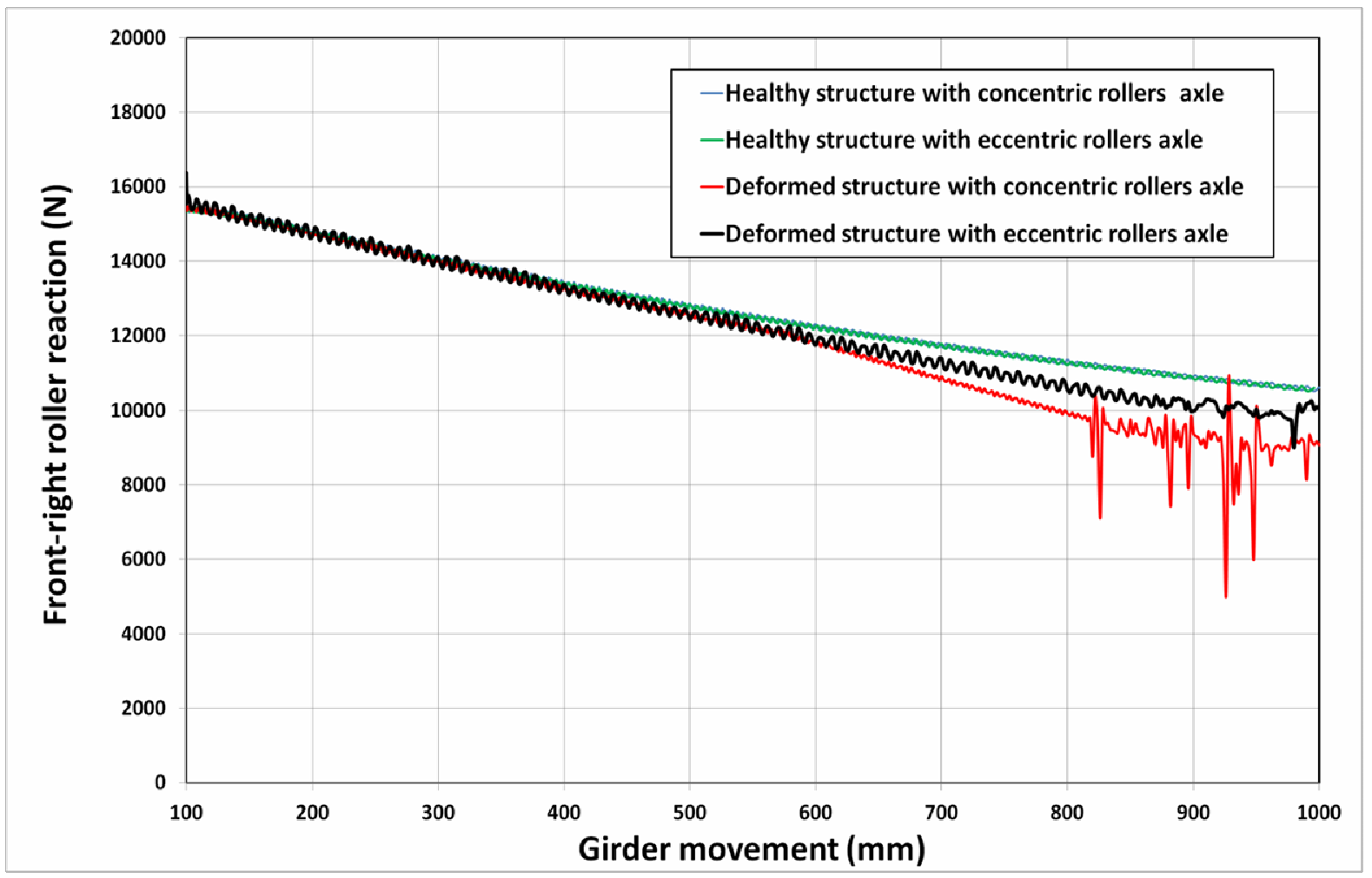

Fig. (11) Front right axle reactions. 


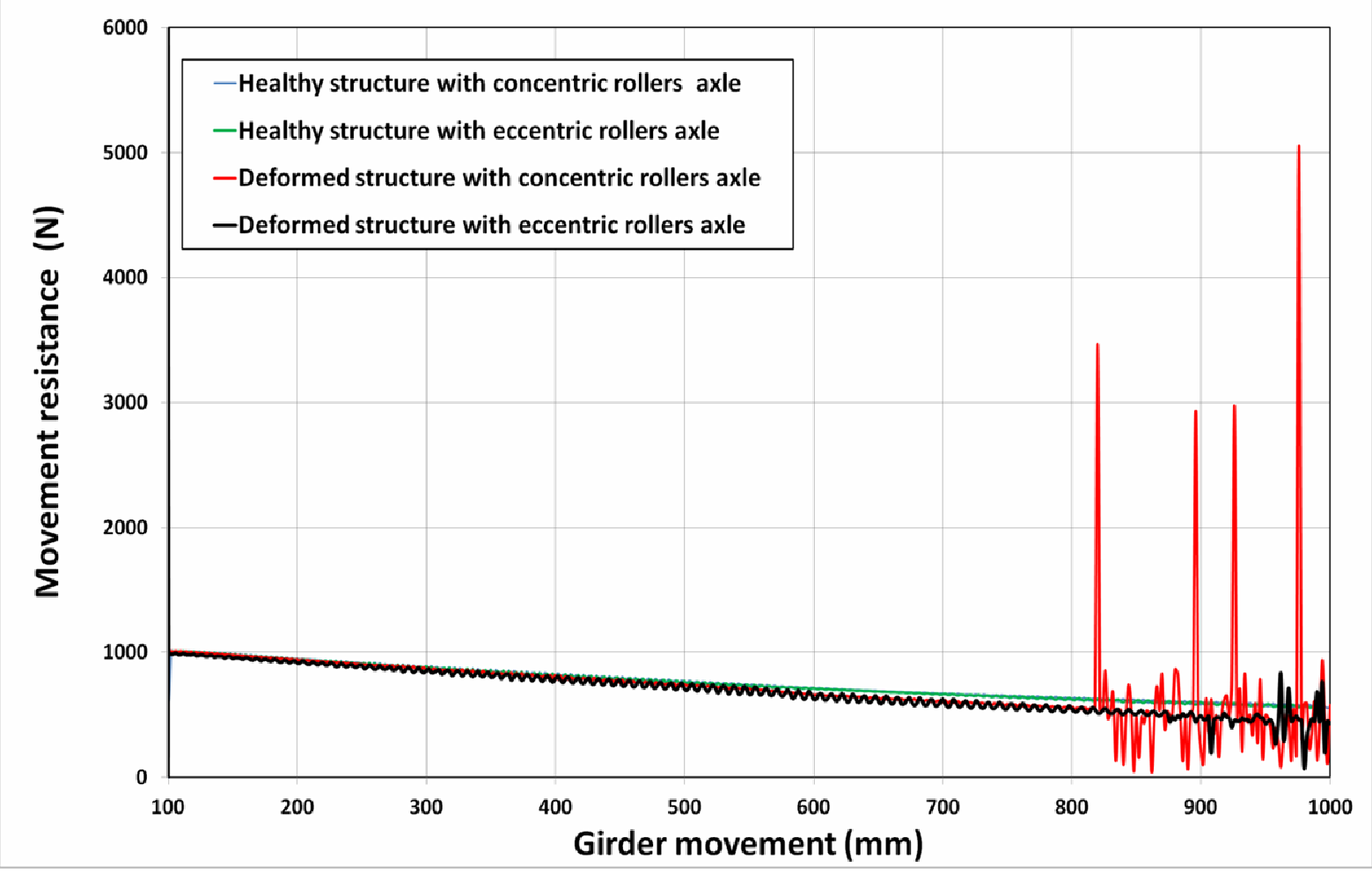

Fig. (12) Launcher resistance forces.

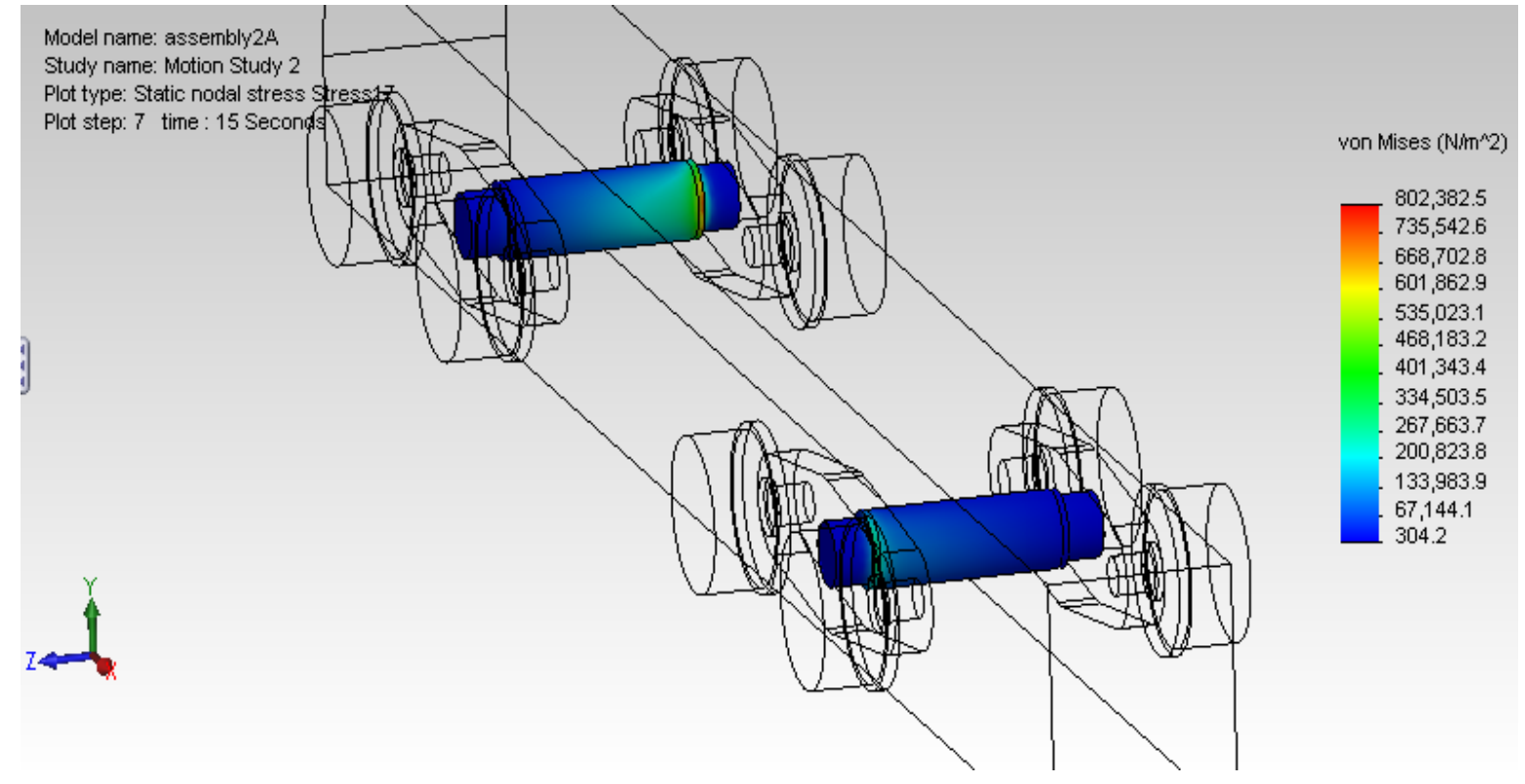

Fig. (13) Rollers axle stress distribution with concentric axle configuration. 


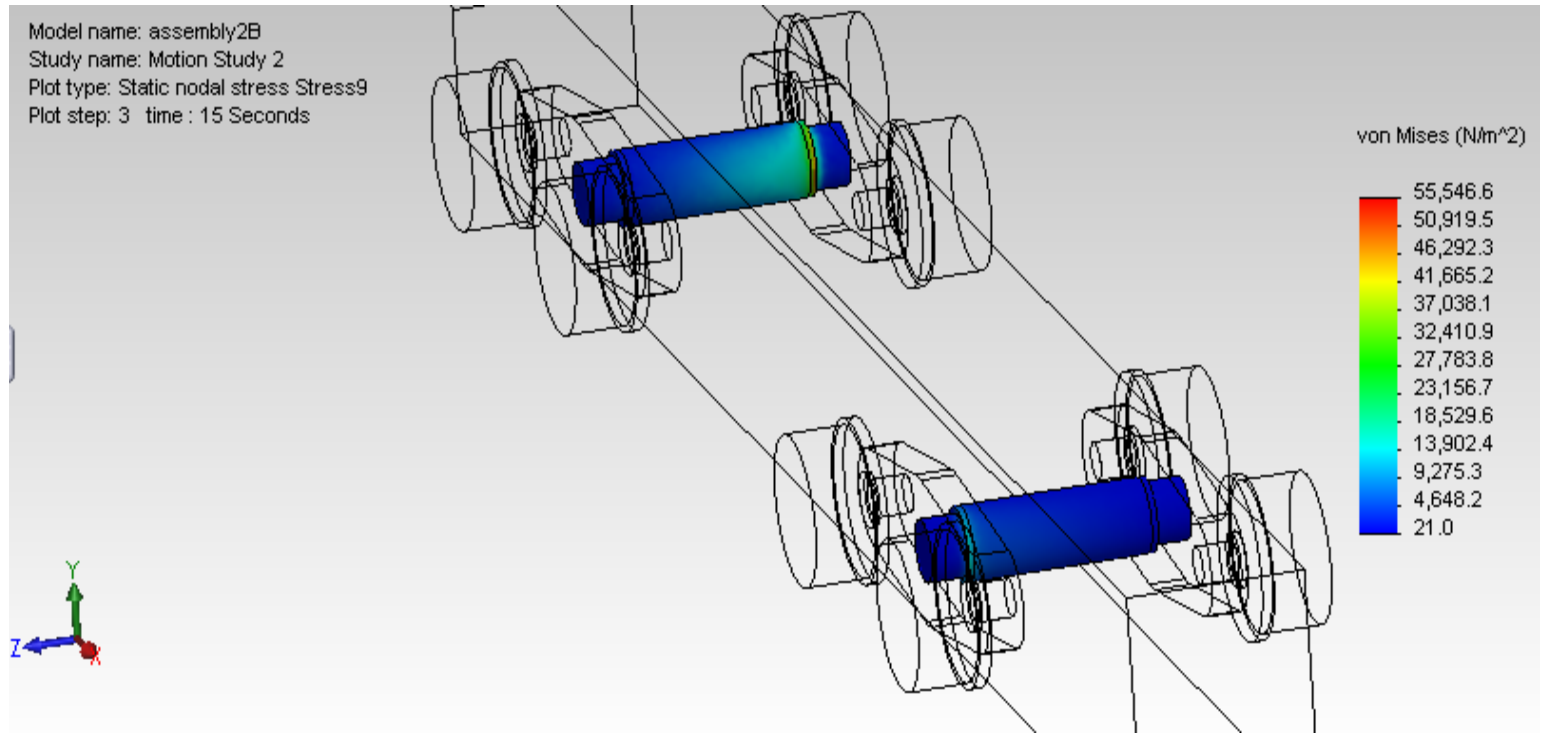

Fig. (14) Rollers axle stress distribution with eccentric axle configuration. 